\title{
Asking the Right Questions when Outsourcing Medical Billing for Oral Appliance Therapy (OAT)
}

\author{
J. Michael Adame, DDS ${ }^{1}$; Michelle Cantwell, DMD²; Kevin Postol, DDS ${ }^{3}$ \\ ${ }^{1}$ Adame Dental Sleep Medicine, ${ }^{2}$ Wellspan Pulmonary and Sleep Medicine, ${ }^{3}$ Sleep Disordered Dentistry, Ballwin, Missouri
}

Unlike most services provided by dentists, OAT is a treatment for a medical disease and may require dentists to navigate the medical insurance system. Medical billing companies can be a resource for those who choose to outsource this activity.

Knowing what to look for in a medical billing company can save your practice from unexpected costs, loss of time, and potential legal issues. Proper vetting is crucial; the dentist is still accountable for the accuracy of claims even if the billing company makes a mistake or does not follow the rules. Keep track of the billing company's answers to these questions and review the final contract to make certain that all of the agreed-to elements are included.

Consider the following information when you evaluate a billing company:

\section{Vetting Potential Medical Billing Companies}

Ask: What is the billing company's experience with coding and billing for dental sleep medicine (DSM)?

Look for: Experienced companies will use the right codes and know the requirements to get claims paid. Whether you choose a billing company that focuses solely on DSM billing or one that has DSM experience as well as other specializations, look for experience specifically in coding and billing for OAT and find out how much of their business is devoted to DSM.

Ask: Have the billing company's clients ever been audited by Medicare or private insurance companies?

Look for: Medical billing companies should be able to provide an overview of how they handle audits and their success rate in passing the audits successfully. If there have been audits, ask for proof that they have passed the audits. If the results themselves cannot be shared due to privacy laws, the billing company should be willing to provide you with a written attestation confirming the audits have been passed.
Ask: Is the billing company insured for errors and omissions? Do they have liability insurance? Are their employees and the billing company bonded? Ask for documentation of each.

Look for: Reputable billing companies have coverage that offers protection in the event an unforeseen error occurs. They will be able to provide proof of insurance, liability coverage, and documentation to demonstrate that employees are appropriately bonded. Review these documents to ensure that the coverage is up to date.

Ask: Will the billing company provide references? Ask for contacts who are in your state and who use the insurers that typically cover your patients. Ask the billing company to include references from both longer term and newer customers.

Look for: Reputable companies will be able to provide you with contact information for current and past customers. Check these references as part of your due diligence. Ask the references any questions you may have about the billing company's timeliness, accuracy, responsiveness, onboarding process and fees.

Ask: What information can the billing company provide about its financial stability?

Look for: Reputable companies will be financially stable and may be willing to provide you with documentation of their financial health, such as audited financial statements or tax returns. Review any financial documents provided to you and check sites like the Better Business Bureau for additional insights.

Ask: How does the billing company respond to questions and how quickly can you expect a response?

Look for: You will want assurance that you can 
quickly and easily access the billing company's staff whenever you have questions, or an issue needs to be addressed. Companies may offer a dedicated account manager you can call, a support team you can contact through email or phone about specific claims, or a message board where you can submit questions. Be sure that the communication methods offered are confidential and the response time quoted meets your practice's needs.

\section{Data Management}

Ask: What are the billing company's compliance procedures? Ask for a copy of the billing company's compliance plan.

Look for: The billing company should follow HIPAA regulations and have procedures for ensuring their billing staff comply with all other regulations. A billing company with a compliance officer and a clearly described internal structure for compliance will be able to keep your practice informed about changes in regulations and can help you respond to audits. You can check to see if a billing company you are considering has been excluded from federally funded health care programs at the website of the Office of Inspector General (OIG) and can check if they are involved in any breaches of protected health information (PHI) at the U.S. Department of Health \& Human Services (HHS) website. You can also check the System for Award Management (SAM) database, maintained by the General Services Administration, to confirm if the billing company has been excluded from receiving federal contracts, subcontracts, or if it has had any suspensions or debarments.

Ask: How is my data managed and what privacy protections are in place? Ask for samples of available reports or a demonstration of the reporting portal.

Look for: The billing company should have a clear process for submitting claims and for resubmitting when a claim is rejected. Verify that rejection and denial rates are not high, as a higher rate may be a sign that the billing company is not using the right codes or including proper documentation. Claims denial rates can vary quite a bit, but a widely cited statistic from the American Academy of Family Physicians indicates that average denial rate for medical claims is $5 \%-10 \%$.

\section{Billing Practices \& Reimbursement}

Ask: How does the billing company ensure they follow the detailed requirements in each insurer's medical policies for OAT? What insurers do they routinely work with?
Look for: The billing company you select needs to know how to navigate policy variations, follow claims guidelines to the last detail, and monitor frequent policy updates. When you talk with potential billing companies, assess whether their staff have the training and experience to find and follow each insurer's rules for proper OAT billing. You or someone on your team will be responsible for providing the billing company with information about your insurance contracts and claims, so make sure you are clear about what your responsibilities will be and what the billing company's responsibilities will be with respect to maintaining current knowledge of the guidelines and requirements.

Ask: What procedure codes does the billing company use when billing an oral appliance for OSA? Ask the billing company to provide a redacted copy of a typical EOB. Ask them to describe their process to ensure coding is correct.

Look for: You need to feel confident that the billing company is using appropriate codes for the services you are providing. Claims that are improperly coded may put your practice at greater risk of claim denials or audits. A reputable billing company will have processes in place (such as internal audits) to check that their staff are not improperly over-coding or under-coding your claims.

Medical claims require one diagnosis code and one procedure code at a minimum. The diagnosis code for obstructive sleep apnea, which comes from the ICD-10$\mathrm{CM}$ coding set, is G47.33. For medical insurance, the appropriate procedure code to use for custom-made oral appliances is E0486. Various HCPCS modifier codes may also be required by specific insurers.

Ask: How does the billing company decide how to submit charges? Does the way they submit charges vary based on the insurance company?

Look for: As you evaluate the billing company's practices, understand how the company handles "bundled" and "unbundled" payments. Bundled payments, which can also be known as episode payments, global payments and case fees (among other terms), are based on the "episode" of care and reimbursement for all services rendered during that episode of care will be bundled together. With unbundled payments, each service you provide can be charged independently.

For Medicare beneficiaries, OAT is covered as a bundled payment that includes both the appliance and office visits. Some commercial insurance companies follow the same rules as Medicare, but others do not. Each insurance company will have specific wording in their 
policies regarding which services are "bundled" in the E0486 code (e.g. office visits, adjustments, procedures), and the billing company should follow each insurer's specific requirements.

The billing company should accept responsibility for reading the insurance contracts and understanding what the insurer considers to be a properly submitted claim (e.g., whether certain services may be bundled or not).

Ask: How does the billing company determine what fee to bill insurers? Ask the billing company to share a copy of the explanation of benefits (EOB) for the type of services you usually provide.

Look for: You may provide a discount to patients paying a cash fee with no insurance reimbursement expected, but the fee for your services should be similar whether covered by insurance or paid for entirely out of pocket by the patient. Review the sample EOBs provided by the billing company and make sure EOBs are easily accessible to your practice once you have signed up with the service, so you can monitor what the billing company is charging insurers and ensure they are not exceeding your out-of-pocket rate.

Ask: What is the billing company's claims process and their rate of rejected and denied claims?

Look for: The billing company should have a clear process for submitting claims and for resubmitting when a claim is rejected. Verify that rejection and denial rates are not high, as a higher rate may be a sign that the billing company is not using the right codes or including proper documentation. Claims denial rates can vary quite a bit, but a widely cited statistic from the American Academy of Family Physicians indicates that average denial rate for medical claims is $5 \%-10 \%$.

Ask: What NPI will the billing company use when processing claims?

Look for: The claim form should list the NPI number for you or your practice as the rendering provider. If the rendering provider is not your or your practice, you will need to follow up to make sure you clearly understand why this is not the case.

Companies that offer to pay you but are not billing under your NPI number may be engaging in pass-through billing. Pass-through billing is denounced by the American Medical Association as unethical and is prohibited by
Medicare. Medicare beneficiaries can be billed only under the name of the supplier who performed the services (e.g., the dentist) and the fee that you pay to the billing company cannot be dependent upon the amount the billing company has collected on your behalf. Many commercial insurance companies have policies that prohibit pass-through billing. Likewise, many states have statutes that do not allow feesplitting. This type of arrangement may also be prohibited under the Federal Anti-Kickback statute. Ultimately, you should expect to always be listed as the rendering provider, if you have provided the service, unless you have thoroughly explored another proposed option with your own legal counsel. The billing company should be willing to certify that they will not violate any state or federal fraud and abuse law or commit any other fraudulent acts.

\section{Services and Costs}

Ask: What is the cost of the billing company's services?

Look For: Billing companies use a variety of ways to charge for their services. Common options include monthly subscription, annual fee, or per-claims pricing. Some companies charge a larger initiation fee at first and then follow with a lower annual fee.

Some companies offer multiple pricing options, others offer only one pricing method. As you review the pricing information, pay attention to when the fees are charged and how the rates may change with the number of claims submitted by your practice.

Ask: What services are provided?

Look For: Understand which services are included in the pricing plans you are considering. Some common services are:

- Credentialing with commercial insurance carriers

- Online and in-person staff training

- Dedicated account manager to work with the practice

- Secure electronic medical records (EMR) systems for sharing patient files and records

- Verification of patient benefits

- Assistance with patient pre-authorizations and gap exception requests (i.e., a waiver from an insurance company that allows a customer to receive medical services from an out-of-network provider at an in-network rate)

- Electronic submission of claims

- Reporting on the status of claims

- Assistance with appeals for both preauthorization and claim reimbursement 
Ask: Can the billing company help you with Medicare enrollment or contracting with commercial insurers' medical networks? Are there additional fees for this service?

Look for: If the billing company offers assistance with enrollment and contracting make sure to understand specifically how they help. The contracting should be focused on billing the E0486 code and for the typical evaluation and management (E/M) codes used for the clinical visits as allowed by some commercial insurance policies. To verify that this is the case, request a redacted copy of a claim from another client receiving the same services you are considering.

Ask: What is the average turnaround time for the billing company to process and fulfill requests?

Look for: The billing company should be able to provide their average time from submission of the claim to your receipt of the funds. Expect the billing company to include information on how they track claims and examples of the procedures they follow when claims delays occur.

Ask: What training will be provided by the billing company?

Look for: The onboarding process with a new billing company should include training for you and your staff on how to interact with its representatives and how to use any software they provide. In addition, explore what resources the billing company can provide so that you have up-todate resources and information on the coding, billing, and documentation requirements needed for successful claims processing. Make sure you have someone on your staff who is familiar with billing for these services and understands how to submit proper documentation to the billing company. This person will also be your key contact, responsible for sharing information with the billing company.

$-\cdot-\cdot-$

As you gather and review information from potential billing companies, have your own legal counsel review all this information. Billing companies may offer to provide advice from their attorney but remember that this counsel is representing the billing company - not you. Your attorney can also help you understand your level of liability in the event the billing company makes an error, as you are ultimately responsible for the accuracy of the billing for services you provide. Any potential or perceived fraud may expose you to criminal, civil, and administrative liability, and may lead to imprisonment, fines, and penalties.

Once you have selected a billing company to work with, also engage your own legal counsel to review the contract. You will want to ensure that all of the information and commitments provided by the billing company in their proposals and communications to you is reflected in the contract before you sign it.

Some of this information and the terms may be new to you if you are just getting started in DSM. AADSM members can download the OAT Reimbursement Guide for details about OAT reimbursement and a glossary of related terms that may be helpful to know as you evaluate medical billing companies.

The information provided in this article should not be construed as legal advice or a legal opinion. Consult a lawyer concerning your specific situation or legal questions. Neither the authors nor AADSM are undertaking to render specific billing or coding advice. You must rely solely on your own judgment to determine what billing practices and procedures are appropriate for your practice. State law varies. Each practice must establish its own policies and procedures regarding appropriate billing for procedures and services in compliance with all applicable state and federal law. The information presented in this article was obtained from sources believed to be reliable. However, applicable laws, regulations and practices are subject to change and the information presented is only current as of the date of publication.

Disclaimer: The opinions expressed in this article do not reflect the position or policies of WellSpan Health and do not necessarily reflect the position or policies of the AADSM Board of Directors.

\section{CITATION}

Adame JM, Cantwell M, Postol K. Asking the right questions when outsourcing medical billing for oral appliance therapy (OAT). J Dent Sleep Med. 2021;8(4).

\section{SUBMISSION AND CORRESPONDENCE INFORMATION}

\section{Submitted June 10, 2021 \\ Submitted in final revised form October 5, 2021 Accepted for publication October 6, 2021}

Address correspondence to: J. Michael Adame, DDS; Email: jma@jmichaeladamedds.com 


\section{DISCLOSURE STATEMENT}

All authors are members of the American Academy of Dental Sleep Medicine Board of Directors. 